\title{
A new intervarietal linkage map and its application for quantitative trait locus analysis of "gigas" features in bread wheat
}

\author{
Kazuhiro Suenaga, Mireille Khairallah, H.M. William, and David A. Hoisington
}

\begin{abstract}
A doubled-haploid (DH) population from an intervarietal cross between the Japanese cultivar 'Fukuhokomugi' and the Israeli wheat line 'Oligoculm' was produced by means of wheat $\times$ maize crosses. One hundred seven DH lines were genotyped to construct a simple sequence repeat (SSR) based linkage map with RFLP, RAPD, and inter-simple sequence repeat markers. Out of 570 loci genotyped, 330 were chosen based on their positions on the linkage map to create a "framework" map for quantitative trait locus (QTL) analysis. Among the 28 linkage groups identified, 25 were assigned to the 21 chromosomes of wheat. The total map length was $3948 \mathrm{cM}$, including the three unassigned linkage groups $(88 \mathrm{cM})$, and the mean interval between loci was $12.0 \mathrm{cM}$. Loci with segregation distortion were clustered on chromosomes $1 \mathrm{~A}, 4 \mathrm{~B}, 4 \mathrm{D}, 5 \mathrm{~A}, 6 \mathrm{~A}, 6 \mathrm{~B}$, and $6 \mathrm{D}$. After vernalization, the DH lines were evaluated for spike number per plant (SN) and spike length (SL) in a greenhouse under 24-h daylength to assess the "gigas" features (extremely large spikes and leaves) of 'Oligoculm'. The DH lines were also autumn-sown in the field in two seasons (1990-1991 and 1997-1998) for SN and SL evaluation. QTL analysis was performed by composite interval mapping (CIM) with the framework map to detect QTLs for SN and SL. A major QTL on 1AS, which was stable in both greenhouse and field conditions, was found to control SN. This QTL was close to the glume pubescence locus $(H g$ ) and explained up to $62.9 \%$ of the total phenotypic variation. The 'Oligoculm' allele restricted spike number. The SSR locus Xpsp2999 was the closest locus to this QTL and is considered to be a possible marker for restricted tillering derived from 'Oligoculm'. Eight QTLs were detected for SL. The largest QTL detected on 2DS was common to the greenhouse and field environments. It explained up to $33.3 \%$ of the total phenotypic variation. The second largest QTL on 1AS was common to the greenhouse and the 1997-1998 season. The position of this QTL was close to that for the SN detected on $1 \mathrm{AS}$. The association between SN and SL is discussed.
\end{abstract}

Key words: linkage map, microsatellite, QTL, spike length, spike number.

Résumé : Une population d'haploïdes doublés (HD) issus d'un croisement intervariétal entre le cultivar japonais 'Fukuho-komugi' et la lignée israélienne 'Oligoculm' a été produite en faisant appel aux croisements blé-maïs. Cent sept lignées HD ont été génotypées pour produire une carte génétique à base de microsatellites mais également de marqueurs RFLP, RAPD et ISSR. Des 570 marqueurs analysés, 330 ont été retenus pour la carte cadre pour fins d'analyse QTL en raison de leur position. Parmi les 28 groupes de liaison identifiés, 25 ont été assignés à l'un des 21 chromosomes du blé. La carte totalise $3948 \mathrm{cM}$, incluant les trois groupes non-assignés à un chromosome $(88 \mathrm{cM})$, et la distance moyenne entre les locus est de 12,0 cM. Les locus montrant une distorsion étaient concentrés sur les chromosomes $1 \mathrm{~A}$, $4 \mathrm{~B}, 4 \mathrm{D}, 5 \mathrm{~A}, 6 \mathrm{~A}, 6 \mathrm{~B}$ et $6 \mathrm{D}$. Après vernalisation, les lignées HD ont été cultivées en serre sous éclairage continu (24 h) afin d'évaluer le caractère 'gigas' (épis et feuilles de grande taille) provenant du parent 'Oligoculm'. Pour ce faire, le nombre d'épis par plante et la longueur des épis ont été relevés. Les lignées HD ont également été semées à l'automne au champ lors de deux années (1990-91 et 1997-98) pour fins d'évaluation du nombre et de la taille des épis. Des analyses QTL ont été réalisées par cartographie composite d'intervalles (CIM) à l'aide des marqueurs de la carte cadre pour détecter des QTL pour les deux caractères. Un QTL majeur, situé sur le chromosome 1AS, a été détecté de manière stable pour le nombre d'épis tant dans les conditions contrôlées (serre) qu'au champ. Ce QTL est situé à proximité du locus déterminant la pubescence des glumes $(H g)$ et expliquait jusqu'à $62,9 \%$ de la variation phénotypique totale et l'allèle d' 'Oligoculm' limitait le nombre d'épis. Le microsatellite Xpsp2999 était le plus fortement lié à ce QTL et peut être considéré comme un marqueur pour le tallage réduit dérivé de la lignée 'Oligoculm'. Huit QTL ont été détectés pour la taille de l'épi et le plus important de ceux-ci était situé sur 2DS tant en serre qu'au champ. Il

Received 18 February 2004. Accepted 15 September 2004. Published on the NRC Research Press Web site at http://genome.nrc.ca on 11 February 2005.

K. Suenaga, ${ }^{1,2}$ M. Khairallah, ${ }^{3}$ H.M. William, and D.A. Hoisington. International Maize and Wheat Improvement Center (CIMMYT), Apdo. Postal 6-641, 06600, Mexico, D.F., Mexico.

${ }^{1}$ Corresponding author (e-mail: suenagak@affrc.go.jp).

${ }^{2}$ Present address: Japan International Research Center for Agricultural Sciences (JIRCAS), 1-1 Ohwashi, Tsukuba, Ibaraki 305-8686, Japan.

${ }^{3}$ Present address: Sicomoro No. 17, Col. Arboledas, Querétaro, CP 76140, QRO, Mexico. 
permettait d'expliquer jusqu'à 33,3\% de la variation phénotypique totale. Le deuxième QTL en importance était situé sur 1AS et a été détecté en serre et au champ en 1997-98. La position de ce QTL est proche du QTL détecté pour le nombre d'épis sur le chromosome 1AS. Cette association entre le nombre et la taille des épis est discutée.

Mots clés : carte génétique, microsatellite, QTL, longueur de l'épi, nombre d'épis.

[Traduit par la Rédaction]

\section{Introduction}

The use of various molecular marker techniques, such as random amplified polymorphic DNA (RAPD), restriction fragment length polymorphism (RFLP), amplified fragment length polymorphism (AFLP), and simple sequence repeat or microsatellite (SSR) markers, has enabled the construction of genetic linkage maps in wheat. Several RFLP-based genetic maps are available, constructed using interspecific/wide crosses (Gale et al. 1995; Liu and Tsunewaki 1991; Marino et al. 1996; Messmer et al. 1999; Nelson et al. 1995a, 1995b, 1995c; Van Deynze et al. 1995) and intervarietal crosses for bread wheat (Cadalen et al. 1997) and durum wheat (Nachit et al. 2001). Since RFLP markers show low levels of polymorphism in wheat and are laborious to use, polymerase chain reaction (PCR) based markers such as AFLP and SSR markers are being used with increasing frequency to construct genetic maps (Röder et al. 1998; Chalmers et al. 2001; Paillard et al. 2003). These genetic maps are useful tools, enabling the tagging of agronomically important genes and the characterization of complex traits, and they form the basis for map-based cloning of genes of interest (Anderson et al. 2001; Huang et al. 2003; Ling et al. 2003; Peng et al. 2000; Sourdille et al. 2000; Williams et al. 2002).

For potentially greater grain yield, Donald (1968) described a wheat ideotype featuring a single strong semidwarf culm, a large spike, and erect leaves. Atsmon and Jacobs (1977) selected wheat lines from a North African wheat cultivar and its derivatives, which, in part, resembled Donald's ideotype. These wheats showed either a single tiller (uniculm) or a restricted number of tillers (oligoculm) with extremely large ("gigas") spikes and leaves. The gigas features may be promising traits for high yield potential in wheat. The International Maize and Wheat Improvement Center (CIMMYT) has also exploited various germplasms to develop new gigas types of wheat with larger sink capacities, a large number of grains per spike, and large grain size potential (Rajaram and van Ginkel 1996). These wheats, once successfully developed and deployed, would offer vastly increased yield potential with increased grain number and (or) grain weight (Richards 1988).

Richards (1988) performed genetic analyses using the gigas lines developed by Atsmon and Jacobs (1977) and demonstrated that the tiller inhibition was controlled by a single recessive gene (Tin), which was linked to the gene for glume pubescence $\mathrm{Hg}$ ) on chromosome 1AS. There was an association between tiller inhibition and large spike size, which may be required to compensate for the restricted tiller number (Richards 1988).

One of the gigas lines of Atsmon and Jacobs (1977) with the oligoculm trait and gigas features was used as a parent of the mapping population in this study. This Israeli line was crossed with the Japanese cultivar 'Fukuho-komugi', which shows normal tillering ability and spike size and is considered to be distant from 'Oligoculm' in its pedigree. A doubled-haploid $(\mathrm{DH})$ population was developed and found to vary in many traits, including agronomic traits and disease resistance. We report here the construction of a genetic linkage map using various sources of SSR markers and the application of the map to the detection of quantitative trait loci (QTL) for tillering ability and spike length (SL) that was chosen to assess the gigas features of 'Oligoculm' in this DH population.

\section{Materials and methods}

\section{Plant materials}

A $\mathrm{DH}$ population was produced from an $\mathrm{F}_{1}$ combination between the Japanese cultivar 'Fukuho-komugi' and an Israeli wheat line with gigas features (Atsmon and Jacobs 1977), denoted as 'Oligoculm' in this study, by means of wheat $\times$ maize crosses (Suenaga and Nakajima 1993). One hundred and seven DH lines were used to construct a genetic linkage map using RAPD, inter-simple sequence repeat (ISSR), RFLP, and SSR loci and for evaluation of spike number per plant (SN) and SL.

\section{Genotyping}

DNA extraction and RFLP detection followed the procedures detailed in Hoisington et al. (1994). Genomic DNA was extracted from 300-400 mg of lyophilized leaf tissue, and 20 $\mu \mathrm{g}$ of DNA was digested with DraI, EcoRI, EcoRV, HindIII, and $X b a \mathrm{I}$. Digested DNA was separated in $0.7 \%$ agarose gel (20 cm wide $\times 5 \mathrm{~cm}$ long). DNA blotted on noncharged nylon membranes was hybridized with probes (100-200 ng/mL) labeled with $5 \%$ digoxigenin. After treatment with anti-digoxigenin and disodium 3-(4-methoxyspiro\{1,2-dioxetane-3,2 $2^{\prime}\left(5^{\prime}\right.$ chloro)tricyclo[3.3.1.1 $\left.1^{3,7}\right]$ decan $\left.\}-4-y l\right)$ phenylphosphate, the membrane was exposed for several hours to overnight on Xray films. One hundred and eighty RFLP probes were screened for parental polymorphisms, and 47 probes were chosen and used for genotyping the population. RFLP probes were kindly provided by Dr. M.E. Sorrells, Cornell University, Ithaca, New York (bcd, cdo, and wg), Dr. K. Tsunewaki, Kyoto University, Kyoto, Japan (pTAG), Dr. M. Gale, John Innes Centre, Norwich, UK (psr), Dr. P. Leroy, National Institute of Agricultural Research, Clermont Ferrand, France (fba and fbb), and Dr. B.S. Gill, Kansas State University Manhattan, Kansas (ksu).

The same genomic DNA was used for SSR analysis. PCRs were performed in a volume of $12.5 \mu \mathrm{L}$ containing $0.25 \mu \mathrm{mol} / \mathrm{L}$ each forward and reverse primers, $2.5 \mathrm{mmol} / \mathrm{L}$ $\mathrm{MgCl}_{2}, 0.2 \mathrm{mmol} / \mathrm{L}$ each deoxynucleotide, $4 \%$ glycerol, 0.625 unit of Taq polymerase, and $25 \mathrm{ng}$ of DNA. A modi- 
fied "touchdown" (Don et al. 1991) program was used: $94{ }^{\circ} \mathrm{C}$ for $2 \mathrm{~min}$, seven cycles of $94{ }^{\circ} \mathrm{C}$ for $1 \mathrm{~min}, 64^{\circ} \mathrm{C}$ (minus $1{ }^{\circ} \mathrm{C}$ per cycle) for $1 \mathrm{~min}$, and $72{ }^{\circ} \mathrm{C}$ for $1 \mathrm{~min}, 35 \mathrm{cy}-$ cles of $94{ }^{\circ} \mathrm{C}$ for $1 \mathrm{~min}, 57{ }^{\circ} \mathrm{C}$ for $1 \mathrm{~min}$, and $72{ }^{\circ} \mathrm{C}$ for $1 \mathrm{~min}$, and finally $72{ }^{\circ} \mathrm{C}$ for $5 \mathrm{~min}$. Depending on the first PCR results, the initial annealing temperature was either increased or decreased by $5{ }^{\circ} \mathrm{C}$. PCR products were separated on small $(14 \mathrm{~cm} \times 12 \mathrm{~cm})$ polyacrylamide gels (AE-6220) (Atto Corporation, Tokyo, Japan) under denaturing or nondenaturing conditions. For denaturing gels, $7 \mu \mathrm{L}$ of DNA sequencing stop solution $(10 \mathrm{mmol} / \mathrm{L} \mathrm{NaOH}, 95 \%$ formamide, $0.05 \%$ bromophenol blue, and $0.05 \%$ xylene cyanol) was added to $12.5 \mu \mathrm{L}$ of PCR products. The mixture was then denatured at $95{ }^{\circ} \mathrm{C}$ for $5 \mathrm{~min}$ and $5 \mu \mathrm{L}$ of denatured sample was loaded on 6\% 19:1 acrylamide-bisacrylamide gel containing $42 \%$ urea. For nondenaturing gels, $2 \mu \mathrm{L}$ of $50 \%$ glycerol with $0.05 \%$ bromophenol blue and $0.05 \%$ xylene cyanol was added to the PCR products. Five microlitres of each sample was loaded on either $8 \%$ or $12 \%$ 29:1 acrylamide-bis-acrylamide gel. Gels were run in TBE $(0.09 \mathrm{~mol} / \mathrm{L}$ Tris-borate and $2 \mathrm{mmol} / \mathrm{L}$ EDTA, $\mathrm{pH}=$ 8.0) until the xylene cyanol reached about $2 \mathrm{~cm}$ from the bottom of the gels. The voltage was kept at 350-450 V to maintain the temperature of the buffer at $55-65{ }^{\circ} \mathrm{C}$ during the separation for denaturing conditions and at $250 \mathrm{~V}$ for nondenaturing conditions. Gels were silver stained following the method of Sanguinetti et al. (1994) with a few modifications; $0.2 \% \mathrm{AgNO}_{3}$ aqueous solution was used and development was stopped with $3 \% \mathrm{Na}_{2}$ EDTA.

To detect polymorphisms between the parental lines, we screened 715 SSR primers. Of these, 400 were used to genotype the DH lines. The primers came from several collections: WMC (Wheat Microsatellite Consortium, P. Isaac, Agrogene, France), GWM (Röder et al. 1998), GDM (Pestsova et al. 2000), PSP (Stephenson et al. 1998), and Cornell University (Ma et al. 1996). Aliquots of PSP primers were kindly provided by Dr. M.D. Gale, John Innes Centre, Norwich, UK. The sequences of GWM primers with a number higher than GWM674 and all of GDM (later published by Pestsova et al. 2000) were kindly provided by Dr. M.S. Röder, Institute for Plant Genetics and Crop Research, Gaterleben, Germany, under a material transfer agreement with CIMMYT.

For RAPD analysis, polymorphisms from 337 Operon 10nucleotide primers (Operon Technologies, Alameda, California) were investigated in $1.5 \%$ agarose gels with ethidium bromide staining. An additional nine Operon primers and three 12-nucleotide primers (Bex, Tokyo, Japan) were analyzed with and without a primer (5'-CCACTCTCTCT-3') modified from ISSR primer K7 (Wu et al. 1994). Polymorphisms were detected on 12\% 39:1 acrylamide-bisacrylamide gel under nondenaturing conditions with silver staining. Loci derived from RAPD-ISSR primer combinations were designated as $X c t$ followed by RAPD primer names and fragment sizes if available.

\section{Agronomic evaluations}

The DH lines were evaluated under greenhouse conditions with two replicates. Germinated seeds of the $\mathrm{DH}$, parental, and $\mathrm{F}_{1}$ plants were vernalized at $4{ }^{\circ} \mathrm{C}$ for 7 weeks (replication1) and 6 weeks (replication 2) immediately after germi- nation in Petri dishes. The vernalized seedlings were transplanted into pots on 13 March 2003 (replication 1) and 20 March 2003 (replication 2) (northern spring). Two seedlings of each DH line were planted in a hill in 16-cm-diameter pots (approximately $4 \mathrm{~L}$ ). One hill represented one DH line in each replication. Four hills (eight plants) each of the parents and $F_{1}$ were also grown in each replication. Each pot had two hills, and thus two DH lines, or four plants. Pots were arranged in rows with approximately $60 \mathrm{~cm}$ distance between rows. The plants were grown under 24-h daylength with supplementary light (approximately 5000 lx) from incandescent lamps during the night. The temperature of the greenhouse was maintained as low as the temperature outside. The 24-h mean temperature ranged from 3.8 to $18.5^{\circ} \mathrm{C}$ during the period from transplanting to heading of the latest plant.

The DH lines were also evaluated under field conditions. Plants were space-planted $20 \mathrm{~cm}$ between hills and 70 $80 \mathrm{~cm}$ between rows in November 1990 (no replication) and November 1997 (two replicates) in Tsukuba, Japan. Three to four seeds per hill were sown and the seedlings were thinned at the three-leaf stage to leave one healthy plant per hill. One hill represented one $\mathrm{DH}$ line in each replication. The parents and $F_{1}$ were also planted numbering 20 plants each in 1990 and 30 plants each in 1997. As the population segregates for the semidwarf genes Rht-Bl and RhtDl (Suenaga and Nakajima 1993), the DH lines were arranged according to plant height to minimize the competitive effect from neighboring plants in both the greenhouse and the field.

SL on the longest culm was measured. SL was designated as length from the base of the bottom spikelet to the tip of the top spikelet, excluding awns. The number of spikes that were completely exserted from the leaf sheath was counted and designated as $\mathrm{SN}$ to assess tillering ability. Measurements from two plants in each hill in the greenhouse were averaged to obtain SL and SN data for each replication.

\section{Map construction and QTL detection}

MAPMAKER (Lander et al. 1987) was used to analyze data of 570 loci including loci for five grain proteins (Suenaga and Nakajima 1993), glume pubescence $(\mathrm{Hg})$, glume color $(R g)$, and leaf tip necrosis ( $\mathrm{Ltn})$ to create a framework map for QTL detection. The 330 loci on the framework map were chosen based on their map location. A logarithm of the odds threshold value of 2.0 and the Haldane mapping function were used to construct each linkage group.

QTLs were identified by CIM (Zeng 1994; Jiang and Zeng 1995) using a computer program developed by C. Jiang at CIMMYT in 1996. QTL detection by the CIM program using one phenotypic data set was denoted as single analysis, and that using two data sets was denoted as joint analysis. QTLs were detected by joint analysis with data from two replications in the greenhouse. Two sets of data from the field, that is, one from 1990-1991 and the mean of two replications in 1997-1998, were analyzed also by joint analysis. Data in each season were also separately analyzed, that is, by single analysis for 1990-1991 and by joint analysis for 1997-1998.

QTLs were declared as significant when the likelihood ratio statistic exceeded the thresholds of 11.5 for single analysis and 13.8 for joint analysis. These likelihood ratio values 
Table 1. Efficiency of various molecular markers for detecting polymorphism in a 'Fukuho-komugi' $\times$ 'Oligoculm' DH population.

\begin{tabular}{|c|c|c|c|c|c|}
\hline Marker & Detection system & $\begin{array}{l}\text { No. of probes or } \\
\text { primers tested }\end{array}$ & $\begin{array}{l}\text { No. of } \\
\text { polymorphic } \\
\text { probes or primers }\end{array}$ & $\begin{array}{l}\text { No. of } \\
\text { polymorphisms }\end{array}$ & $\begin{array}{l}\% \\
\text { polymorphism }^{a}\end{array}$ \\
\hline $\mathrm{RAPD}^{b}$ & Agarose gels, ethidium bromide & 337 & 30 & 37 & 11.0 \\
\hline RFLP & Chemiluminescence (digoxigenin/anti-digoxigenin) & 180 & 41 & 47 & 26.1 \\
\hline $\mathrm{SSR}^{c}$ & Acrylamide gels, nondenaturing, silver & 192 & 104 & 106 & 55.2 \\
\hline $\mathrm{SSR}^{d}$ & Acrylamide gels, denaturing, silver & 485 & 202 & 266 & 54.9 \\
\hline
\end{tabular}

${ }^{a}$ Number of polymorphisms per number of probes (primers) tested.

${ }^{b}$ From Niwata et al. (1994).

${ }^{c}$ Mainly GWM primers were used.

${ }^{d}$ Mainly WMC primers were used.

were equivalent to a logarithm of the odds score of 2.5. The probability for a type I error over the whole genome was 0.13. Details on the CIM procedure for QTL detection, calculation of genetic effects, and percentage phenotypic variation of the QTLs are described in Ayala et al. (2002).

\section{Results and discussion}

\section{Linkage map}

Traditionally, full linkage maps in wheat are constructed using interspecific and(or) wide crosses owing to the low levels of RFLP among wheat cultivars (Liu and Tsunewaki 1991; Gale et al. 1995; Nelson et al. 1995a, 1995b, 1995c; Van Deynze et al. 1995; Marino et al. 1996; Messmer et al. 1999), although one RFLP-based linkage map for an intervarietal cross has been made (Cadalen et al. 1997). A large number of SSR markers were recently made available in wheat (Ma et al. 1996; Röder et al. 1998; Stephenson et al. 1998; Pestsova et al. 2000; Song et al. 2002; Guyomarc'h et al. 2002; Gupta et al. 2002). These markers have the potential to identify higher levels of polymorphism; this combined with their easier and quicker assay compared with RFLP assays has enabled wheat researchers to use them increasingly in linkage analysis and mapping studies involving intervarietal crosses. They also show a good level of genome specificity and have been successfully incorporated into previous RFLP maps (Röder et al. 1998; Chalmers et al. 2001; Paillard et al. 2003).

Table 1 shows the differences in the efficiency between RAPD, RFLP, and SSR markers in detecting polymorphisms in this particular wheat population. RAPD analysis of 337 primers in agarose gels resulted in an efficiency of $11.3 \%$ (number of polymorphisms per number of primers tested). Only $8.9 \%$ of the primers showed polymorphism between the parents (Niwata et al. 1994). The levels of polymorphism observed with RFLP and SSR markers were $26.1 \%$ and $55.2 \%$, respectively. No large differences were observed between SSR markers in nondenaturing and denaturing polyacrylamide gels. However, it was easier to genotype using denaturing acrylamide gels owing to the smaller number of bands detected in gels.

The DH population was genotyped with 570 loci, including 406 SSR, three sequence tagged site, 47 RFLP, and 106 RAPD and RAPD-ISSR loci. To construct the framework map for the QTL analysis, we chose 330 loci including 278 SSR loci on the basis of their map location; these are shown in bold type in Fig. 1. Loci that could not be incorporated into a unique position were not included in the map. Eightytwo SSR and 20 RFLP loci whose distance to flanking framework loci was $2.0 \mathrm{cM}$ or less are indicated at corresponding loci or intervals in normal type. The approximate position of leaf tip necrosis (Ltn), the visible marker associated with the important durable rust resistance genes Lr34/Yrl8 (Singh 1992a, 1992b), is also indicated. In total, 433 loci are indicated on the linkage map in Fig. 1.

The 433 loci used on the population resulted in a map with 28 linkage groups, of which 25 were assigned to the 21 chromosomes, while three were not assigned to any chromosome. Linkage groups were assigned to chromosomes when the groups had two or more SSR loci that had been assigned to a particular wheat chromosome in previously published maps. The total map length was $3948 \mathrm{cM}$, including the three unassigned linkage groups $(88 \mathrm{cM})$, and the mean interval between loci was $12.0 \mathrm{cM}$. The length in this study is comparable with those of the previous map (3551 cM) by Nelson et al. (1995a, 1995b, 1995c), Van Deynze et al. (1995), and Marino et al. (1996) and the map (4110 cM) by Chalmers et al. (2001).

The mapped positions of the SSR loci genotyped in this study were compared with those in other maps (Röder et al. 1998; Stephenson et al. 1998; Pestsova et al. 2000; Chalmers et al. 2001; Gupta et al. 2002). Although a precise comparison could not be made because of differences in markers used in each map, most SSR loci showed good consistency of map location. These SSR loci are underlined in Fig. 1.

The total length of the D genome chromosomes was comparable with those of the A and B genomes, being only 20 cM shorter. However, only 84 loci were mapped in the D genome compared with 96 in the A genome and 137 in the B genome. The smaller number of loci in the $\mathrm{D}$ genome is common in other wheat maps (Röder et al. 1998, Chalmers et al. 2001). In addition, the long arms of 5A and 6D in the present map are underrepresented. Four chromosomes (3A, $3 \mathrm{D}, 4 \mathrm{~A}$, and $6 \mathrm{~A}$ ) had gaps in them, being represented by two linkage groups each.

Although most SSR loci were randomly distributed throughout the genome, some loci clustered, especially in the centromeric regions, as illustrated on chromosomes $1 \mathrm{~A}$, 1B, 2A, 3B, 4B, 5B, and 6B (Fig. 1). A similar clustering of SSR loci was shown by Röder et al. (1998). Clustering of RFLP loci was also reported by Gale et al. (1995), Cadalen et al. (1997), and Messmer et al. (1999). The clustering in the centromeric regions is simply considered as a reflection of fewer recombinations than in the distal region of the chro- 
Fig. 1. Microsatellite-based linkage map of 433 marker loci for 21 wheat chromosomes in 107 DH lines derived from a 'Fukuhokomugi' $\times$ 'Oligoculm' cross. Short arms are toward the top. Framework loci used for QTL analysis are in bold type. Loci, linked to framework loci within $2 \mathrm{cM}$, are in normal type and placed at appropriate loci or intervals with vertical bars. Approximate positions of the centromeres are indicated by triangles. Framework loci whose positions were confirmed by previous published maps are underlined. Loci distorted from a 1:1 ratio are denoted by asterisks $(* P=0.05, * * P=0.01$, and $* * * P=0.001$ significance levels). QTLs for SN and QTLs on 1AS and 2DS for SL are indicated on the left of the linkage groups. Reversed letters indicate that the QTLs were detected commonly in the field and the greenhouse. The possible position of Rht8 (Worland et al. 1998) and QTL positions for Ppd-B1 and Ppd-D1 (Suenaga et al. 2002) on the map are also indicated.

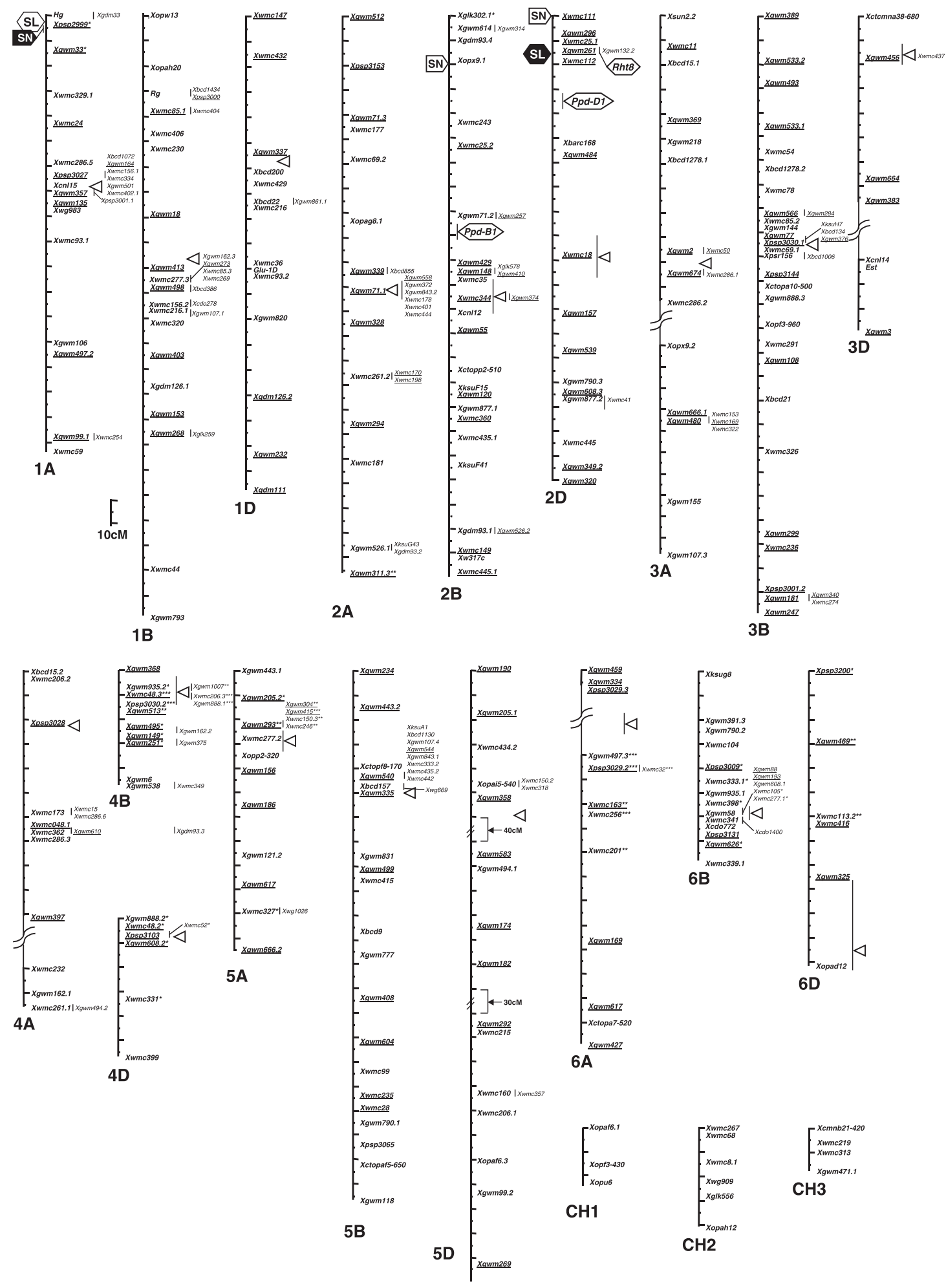


Fig. 1 (concluded).

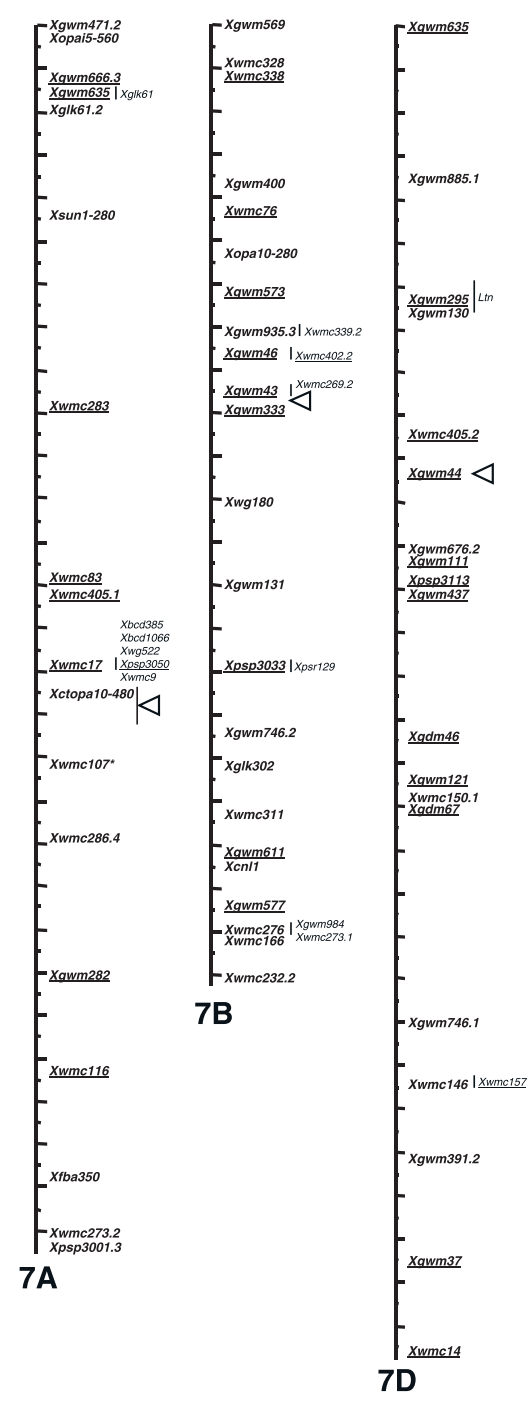

mosomes. This results in noncorrespondence of genetic and physical map distances (Gale et al. 1995). Therefore, it seems that despite the larger number of RFLP and SSR markers now available in wheat, it is still not easy to develop a wheat linkage map with a complete and homogeneous coverage.

Clustering of AFLP loci is also a common phenomenon (Chalmers et al. 2001). However, since a large number of primer combinations can be used in AFLP and ISSR analysis, and the efficiencies of polymorphism have been reported to be fairly high (Chalmers et al. 2001; Reddy et al. 2002), it may be feasible to fill map regions with these markers, where other types of markers are scarce.

\section{Marker distortion}

The mean frequencies in the DH progeny of 'Fukuhokomugi' and 'Oligoculm' marker alleles were $52.2 \%$ and $47.8 \%$, respectively. Of the 433 loci shown in Fig. 1, 43 showed significantly $(P<0.05)$ distorted segregation. The level of distortion is indicated with asterisk(s) following the locus names. Alleles from 'Fukuho-komugi' were favored at all of the distorted loci, except for $X g w m 311.3$ at the distal end of $2 \mathrm{AL}$. The distorted loci were located on chromo- somes 1A, 2A, 2B, 4B, 4D, 5A, 6A, 6B, 6D, and 7A. Most of the distorted loci were clustered on chromosomes (or arms) $1 \mathrm{AS}, 4 \mathrm{~B}, 4 \mathrm{D}, 5 \mathrm{~A}, 6 \mathrm{AL}, 6 \mathrm{~B}$, and 6DS. Clustering of distorted loci on various chromosomes was also reported by Cadalen et al. (1997), Messmer et al. (1999), Kammholz et al. (2001), and Paillard et al. (2003).

The population of this study was developed by means of wheat $\times$ maize crosses (Suenaga and Nakajima 1993). 'Fukuho-komugi' showed significantly higher efficiency than 'Oligoculm' both in embryo formation after crossing with maize and in chromosome doubling (Suenaga et al. 1991; Suenaga and Nakajima 1993). This is consistent with the fact that all of the loci favored the 'Fukuho-komugi' allele, except for Xgwm311.3. Inagaki et al. (1998) demonstrated that chromosomes 4B and 4D had significant effects on the efficiency of wheat haploid production through crossing with maize, which may explain the observed clustering of distorted loci on 4B and 4D in this cross. Gametocidal $(G c)$ and pollen killer $(K i)$ genes have been reported in wheat to be distributed in different homoeologous groups (McIntosh et al. 1998) and may be responsible for distorted segregation. Kammholz et al. (2001) speculated that clustering of distorted loci appeared to be associated with introgressed alien chromatin involving translocations into one of the parents. However, the parents used in this study are not known to have any alien translocations.

Distorted loci may lead to spurious linkages and a reduced estimate of the recombination value (Kammholz et al. 2001). The possibility of spurious linkage by distorted loci in this study was eliminated by comparing the position and order of the loci with those in reported maps. Extreme distortion will also affect QTL analysis, but the level of distortion observed in this study (maximum distortion was approximately 7 to 3 ) may not bias the estimation of QTL effect, although the power of the QTL detection may be reduced by the distortion (C. Jiang, Monsanto, St. Louis, Mo., personal communication).

\section{Agronomic evaluation}

The population exhibited continuous variation for both SN and SL. Figure 2 shows frequency distributions of SN and SL in the greenhouse and those in the 1997-1998 season. The distributions in 1990-1991 were similar to those in 1997-1998 (data not shown). Very few DH lines showed lower SN or larger SL than 'Oligoculm' (Fig. 2), indicating that most of the genes responsible for restricted tillering and large spikes are derived from 'Oligoculm'. 'Fukuho-komugi' consistently showed a larger SN than 'Oligoculm'. The SN of the $F_{1}$ plants was higher than the midparent values. The SL of 'Oligoculm' was longer than that of 'Fukuho-komugi' by $4.5 \mathrm{~cm}$ in the greenhouse and by $6-7 \mathrm{~cm}$ in the field. The SL of the $F_{1}$ plants was close to the midparent values in all trials (Table 2). Differences between the parents for both traits were much smaller in greenhouse conditions, probably owing to the shorter growth period.

The heritability of SN and SL for each environment was calculated. Environmental variance was estimated from the variances within the parents or $F_{1}$. Heritability in the greenhouse was 0.91 for SN and 0.71 for SL. Values for SN and $\mathrm{SL}$ in the field ranged from 0.67 to 0.78 . Phenotypic correlations $\left(r_{\mathrm{P}}\right)$ between the data for $\mathrm{SN}$ recorded in different envi- 
Fig. 2. Frequency distribution of spike number per plant and spike length in a DH population from a 'Fukuho-komugi' $\times$ 'Oligoculm' cross.

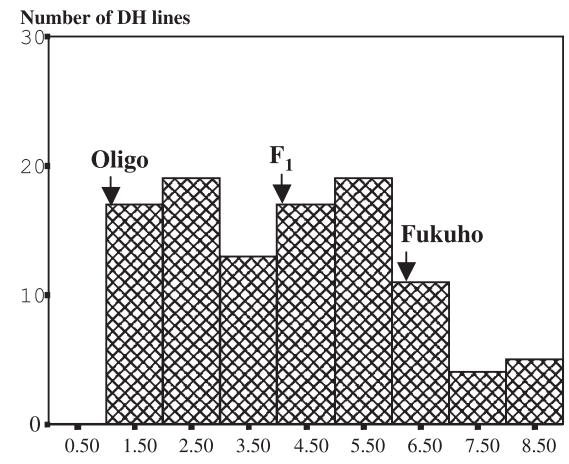

a. Spike number / plant (Greenhouse)
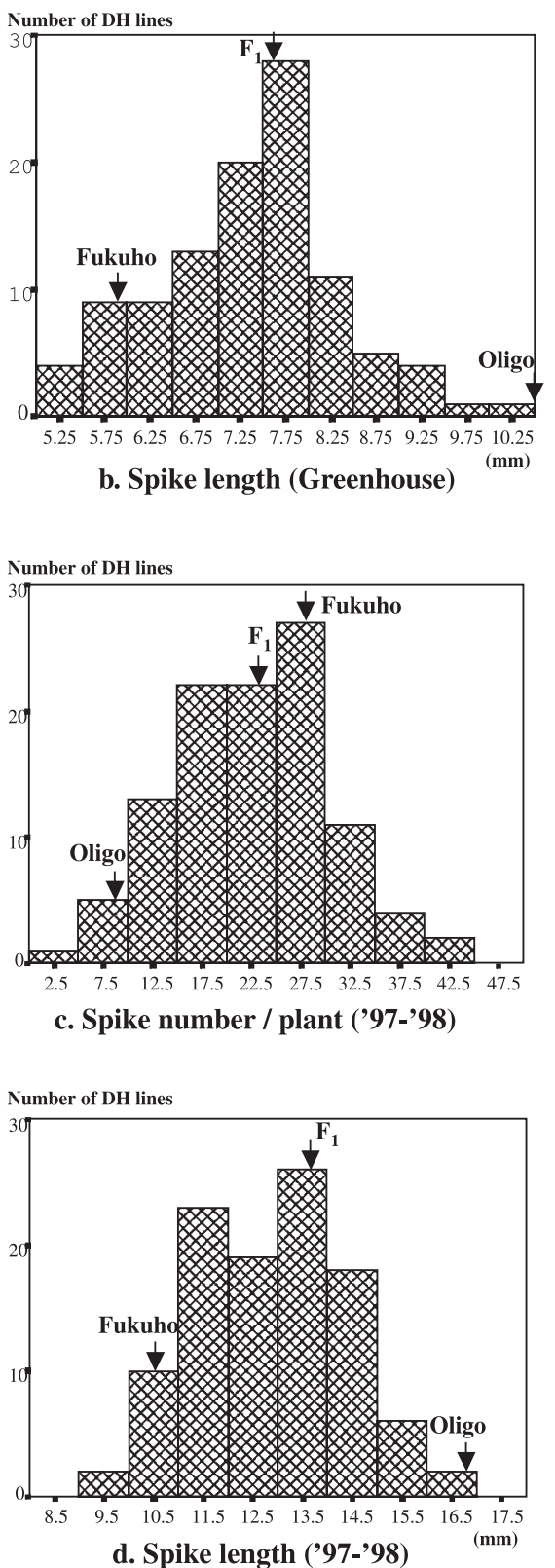

Fig. 3. Likelihood ratio contour for SN and SL by CIM in the distal regions of $1 \mathrm{AS}$ and 2DS in $107 \mathrm{DH}$ lines derived from a 'Fukuho-komugi' $\times$ 'Oligoculm' cross. Distal ends are toward the top. Framework loci are indicated in italic bold type on the left of the figures. The approximate position of a putative QTL for heading date owing to the effects of Ppd-Dl (Suenaga et al. 2002) is also indicated. Likelihood ratio contours are obtained by joint analysis with two data sets. The critical value for the likelihood ratio values (13.8) is indicated by an arrow and is equivalent to a logarithm of the odds value of 2.5. In Fig. $3 a$, the scale for the likelihood ratio contour for $\mathrm{SN}$ greenhouse is indicated at the bottom.

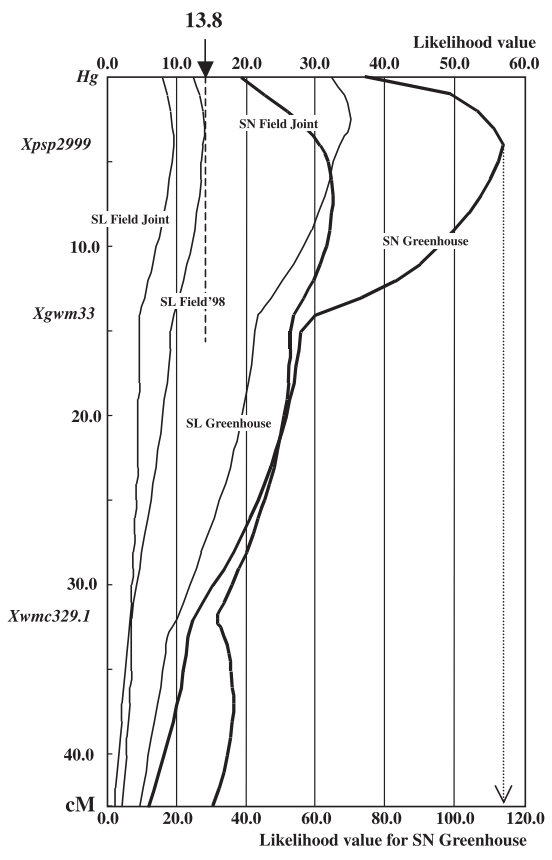

a) Distal end region of Chromosome 1AS

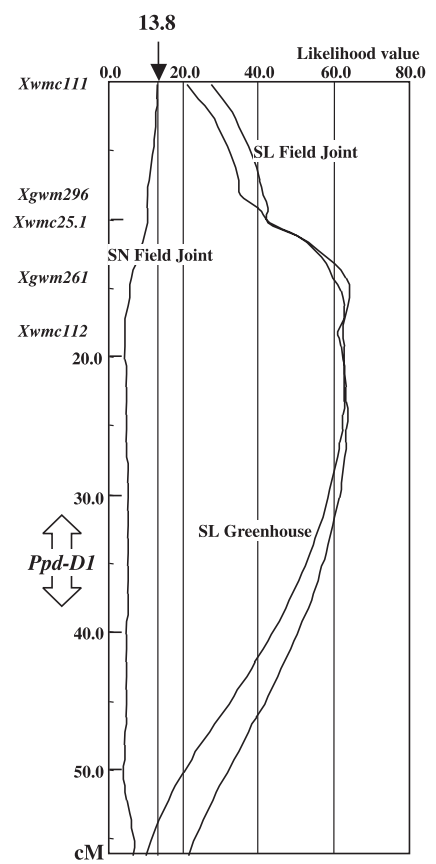

b) Distal end region of Chromosome 2DS 
Table 2. Mean values \pm SE for the parents and $F_{1}$ progeny for spike number per plant and spike length.

\begin{tabular}{|c|c|c|c|}
\hline & \multicolumn{2}{|l|}{ Field $^{a}$} & \multirow[b]{2}{*}{ Greenhouse, $2003^{b}$} \\
\hline & 1990-1991 & $1997-1998$ & \\
\hline \multicolumn{4}{|c|}{ Spike number per plant } \\
\hline 'Fukuho-komugi' & $22.6 \pm 0.7$ & $27.4 \pm 1.4$ & $6.2 \pm 0.3$ \\
\hline 'Oligoculm' & $8.2 \pm 0.5$ & $8.5 \pm 0.9$ & $1.1 \pm 0.1$ \\
\hline $\mathrm{F}_{1}$ & $18.7 \pm 0.9$ & $23.2 \pm 0.7$ & $4.1 \pm 0.4$ \\
\hline Midparent value & 15.4 & 18.0 & 3.7 \\
\hline \multicolumn{4}{|l|}{ Spike length (cm) } \\
\hline 'Fukuho-komugi' & $10.3 \pm 0.2$ & $10.6 \pm 0.2$ & $5.9 \pm 0.1$ \\
\hline 'Oligoculm' & $17.2 \pm 0.2$ & $16.8 \pm 0.3$ & $10.4 \pm 0.2$ \\
\hline $\mathrm{F}_{1}$ & $13.2 \pm 0.2$ & $13.7 \pm 0.2$ & $7.6 \pm 0.1$ \\
\hline Midparent value & 13.8 & 13.7 & 8.2 \\
\hline
\end{tabular}

ronments were $0.63(P<0.001)$ between the $1990-1991$ and 1997-1998 seasons, $0.50(P<0.001)$ between $1990-1991$ and the greenhouse, and $0.51(P<0.001)$ between 19971998 and the greenhouse. SL showed higher correlation coefficients among the three trials $(0.63-0.75, P<0.001)$. No significant phenotypic $\left(r_{\mathrm{P}}\right)$ or genetic correlations $\left(r_{\mathrm{G}}\right)$ were detected between SN and SL in 1990-1991 and 1997-1998, but a significant negative correlation $\left(r_{\mathrm{P}}=-0.365, r_{\mathrm{G}}=-0.380\right.$, $P<0.01)$ was found in the green house, indicating a partial genetic association of these traits.

On the basis of these observations, we cannot establish positively whether there are genetic factors in common controlling SN and SL, but this cannot be completely excluded. Phenotypic data were further analyzed by CIM to identify QTLs for SN and SL.

\section{QTL analysis for gigas features}

\section{Spike number per plant}

Table 3 summarizes the results of QTL analysis for SN and SL. The DH population was evaluated for SN under conditions in which possible effects of the photoperiod response gene Ppd and the vernalization response gene $\mathrm{Vrn}$ on tillering were eliminated. This was done by growing the $\mathrm{DH}$ population in a greenhouse under 24-h daylength after vernalization. Joint analysis for the greenhouse trial with two replications detected two QTLs on 1AS and 2BS (Table 3; Fig. 1). Restricted tillering caused by these two loci was derived from 'Oligoculm'. The effect of the QTL on 1AS was very large with $R^{2}$ values (percent phenotypic variation explained) ranging from $60.5 \%$ to $62.9 \%$ (Table 3; Fig. 3), indicating a limited number of genes involved and (or) small environmental effects under greenhouse conditions. The effects of the QTL on 2BS were much smaller. Its position was approximately $60 \mathrm{cM}$ distal to the QTL for Ppd-B1 (Suenaga et al. 2002), which is considered to display pleiotropic effects on tillering by changing the growth period. Li et al. (2002) reported such effects of Ppd-D1 located on 2DS on tiller number per plant in the International Triticeae Mapping Initiative mapping population.

Joint analysis using the data from the 1990-1991 and 1997-1998 seasons detected two QTLs for SN on 1AS and 2DS. Further analyses performed separately for each season did not detect any additional QTLs. The larger QTL was lo- cated in the distal region of 1AS (Figs. 1 and 3), in agreement with the greenhouse data. The $R^{2}$ values were $16.3 \%$ in 1990-1991 and 25.6\% in 1997-1998 (Table 3).

The second QTL with marginal significance was located in the distal region of 2DS (Figs. 1 and 3). 'Fukuhokomugi', which showed normal tillering, was responsible for the decreased tillering caused by this QTL. Since the position of this QTL was approximately $35 \mathrm{cM}$ from a QTL for heading date owing to the effects of Ppd-Dldetected on the same chromosome arm in the present population (Suenaga et al. 2002) (Figs. 1 and 3), this QTL was considered to be different from $P p d-D 1$.

The QTL on 1AS was stable across different environments in this study (Table 3; Fig. 3). The detection of a major QTL for SN on $1 \mathrm{AS}$ is consistent with the results of Richards (1988), who detected a single recessive gene for tiller inhibition (Tin) in wheat lines of Israeli origin under greenhouse conditions. He also demonstrated that Tin and $\mathrm{Hg}$ were linked at $10 \pm 3$ map units in several populations. $\mathrm{Hg}$ was located at the distal end of $1 \mathrm{AS}$ and linked with the major QTL for SN in this study. As the peak of the QTL contour for $\mathrm{SN}$ was at $4.0 \mathrm{cM}$ from $\mathrm{Hg}$ in the greenhouse and $7.0 \mathrm{cM}$ in the field (Fig. 3), the closest locus was Xpsp2999, which is $4.2 \mathrm{cM}$ proximal to $\mathrm{Hg}$. Although Atsmon and Jacobs (1978) reported that the uniculm and oligoculm traits of Israeli origin were under polygenic control, we detected no stable QTL other than that on $1 \mathrm{AS}$ in this study. They also reported a level of dominance for lower tillering ability. However, the $\mathrm{SN}$ of $\mathrm{F}_{1}$ plants was larger than the midparent value (Table 2), indicating dominance for higher tillering ability under the conditions of the study.

\section{Spike length}

Eight putative QTLs were detected for SL in the greenhouse and field trials. One major QTL on 2DS was common to the greenhouse and field environments. The phenotypic variation explained by this QTL varied from $19.3 \%$ to $33.3 \%$ (Table 3). The position of this QTL was 13-16 cM proximal to that detected for SN in the field (Figs. 1 and 3). The SSR locus $X g w m 261$ was on or close to the peak of the likelihood ratio contour for SL. Xgwm261 is known to be closely linked or cosegregated with the semidwarf gene $R h t 8$, which is possessed by 'Fukuho-komugi' (Worland et al. 1998). These ob- 
Table 3. QTLs detected for spike number per plant and spike length in a 'Fukuho-komugi' $\times$ 'Oligoculm' DH population.

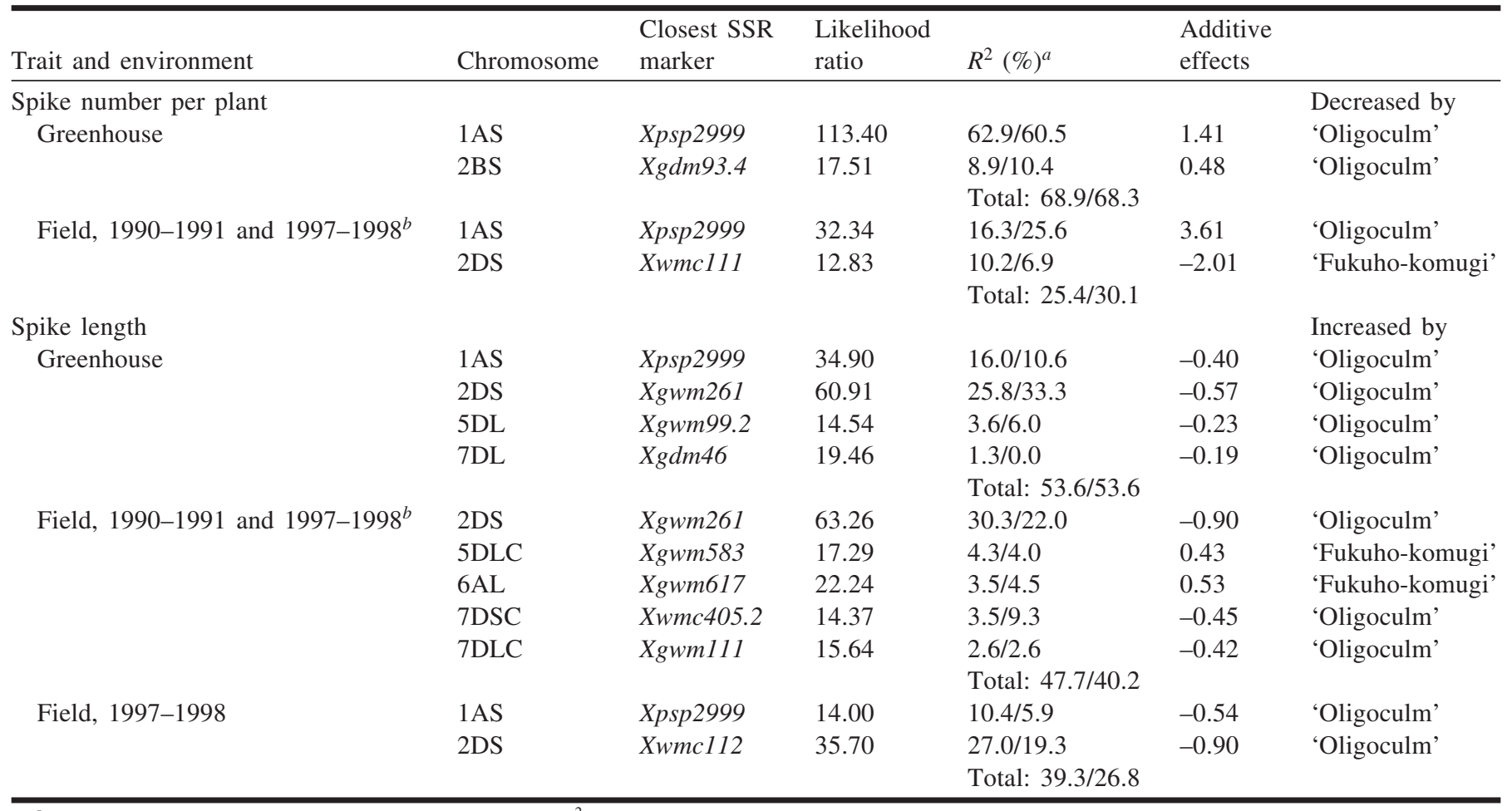

${ }^{a}$ Percent phenotypic variation explained by each QTL; $R^{2}(\%)$ was calculated for each data set.

${ }^{b}$ Joint analysis by two data sets; data of 1990-1991 and the mean of 1997-1998.

servations imply a possible pleiotropic effect of the Rht8 gene on SL. Worland et al. (2001) reported a slight reduction of SL by Rht8, although it was not significant. These observations are consistent with the result that 'Oligoculm' was responsible for increasing SL via this QTL on 2DS (Table 3 ).

Three additional QTLs were found by joint analysis of the greenhouse data. Joint analysis for the 1990-1991 and 1997-1998 seasons detected four other QTLs and that for 1997-1998 detected one additional QTL. The effects of these QTLs were small, and none of them were common in any two of the three trials, except for that on $1 \mathrm{AS}$, which was common to the greenhouse and 1997-1998 (Table 3). These results imply that SL may be controlled by more genes with minor effects than SN and that there may be significant influence by the environment in their expression.

The QTL on 1AS was detected in the same region as that for SN (Figs. 1 and 3). This is consistent with the fact that a significant negative genetic correlation between SN and SL ( $r=-0.38, P<0.01$ ) was found in the greenhouse environment, although no significant genetic correlation was found in the 1990-1991 or 1997-1998 season. Its effects were the second largest, after the QTL on 2DS, with $R^{2}$ values ranging up to $16.0 \%$ for the greenhouse and up to $10.4 \%$ for 1997-1998 (Table 3). 'Oligoculm' increased SL via this QTL. Therefore, although the effects of the QTL were small to intermediate and were found only in two of the three environments, the detection of a common QTL for SN and SL may corroborate the reported association of restricted tillering and large spikes (Atsmon and Jacobs 1977; Richards 1988).
One major QTL responsible for reduced tillering and common to SL was successfully detected on 1AS. Detection of only one common QTL for both traits and other putative QTLs implies that the restricted tillering and large spike size derived from 'Oligoculm' may be controlled also by different genetic mechanisms. However, considering the size of the population (107 DH lines), the effects of QTLs that were not stable across environments should be further verified in a larger population. Furthermore, to verify the validity of Xpsp2999 as a marker for the reduced tillering and the gigas traits of 'Oligoculm', it is necessary to investigate the allelic variation of this SSR in a range of wheat cultivars.

An SSR-based genetic linkage map with 433 loci was successfully constructed, incorporating various sources of SSR markers. Through this map, the gigas features of 'Oligoculm', that is, restricted tillering and large spike, were analyzed by CIM. One major QTL for SN, which seemed to be also responsible for SL, was detected in the distal region of 1AS, where $\mathrm{Hg}$ is located. An SSR locus, Xpsp2999, was found to be closest to this QTL and was considered to be a potential marker for the gigas features of 'Oligoculm'.

\section{Acknowledgements}

The authors are grateful to Dr. C. Jiang, Monsanto, St. Louis, Mo., for the valuable comments on QTL analysis and to Dr. P.J. Sharp, University of Sydney, Sydney, Australia, for critical reading of the manuscript. The authors are also grateful to Dr. Rick Ward, Michigan State University, East Lansing, Michigan, for his providing us information on the SSR primer barc168. We thank Ms. L.E.L. Magaña for the 
technical help with RFLP and SSR analysis and Drs. E. Niwata and T. Ban for their RAPD analysis using agarose gels. We also thank Dr. D. Poland for editorial review. The present study was a collaborative JIRCAS/CIMMYT effort supported by both organizations.

\section{References}

Anderson, J.A., Stack, R.W., Liu, S., Waldron, B.L., Fjeld, A.D., Coyne, C., Moreno-Selilla, B., Fetch, J.M., Song, Q.J., Cregan, P.B., and Frohberg, R.C. 2001. DNA markers for Fusarium head blight resistance QTLs in two wheat populations. Theor. Appl. Genet. 102: 1164-1168.

Atsmon, D., and Jacobs, E. 1977. A newly bred 'gigas' form of bread wheat (Triticum aestivum L.): morphological features and thermo-photoperiodic responses. Crop Sci. 17: 31-35.

Atsmon, D., and Jacobs, E. 1978. Genetic and environmental factors affecting tillering and yield components in uni- and oligoculm bread wheats and in their crosses with standard varieties. In Proceedings of the 5th International Wheat Genetics Symposium, New Delhi, India, 23-28 February 1978. Edited by S. Ramanujam. Indian Society of Genetics and Plant Breeding, New Delhi. pp. 1002-1003.

Ayala, L., Henry, M., van Ginkel, M., Singh, R., Keller, B., and Khairallah, M. 2002. Identification of QTLs for BYDV tolerance in bread wheat. Euphytica, 128: 249-259.

Cadalen, T., Boeuf, C., Bernard, S., and Bernard, M. 1997. An intervarietal molecular marker map in Triticum aestivum L. Em. Thell., and comparison with a map from a wide cross. Theor. Appl. Genet. 94: 367-377.

Chalmers, K.J., Campbell, A.W., Kretschmer, J., Karakousis, A., Henschke, P.H., Pierens, S., Harker, N., Pallotta, M., Cornish, G.B., Shariflou, M.R., Rampling, L.R., McLauchlan, A., Daggard, G., Sharp, P.J., Holton, T.A., Sutherland, M.W., Appels, R., and Langridge, P. 2001. Construction of three linkage maps in bread wheat, Triticum aestivum. Aust. J. Agric. Res. 52: 1089-1119.

Don, R.H., Cox, P.T., Wainwright, B.J., Baker, K., and Mattick, J.S. 1991. 'Touchdown' PCR to circumvent spurious priming during gene amplification. Nucleic Acids Res. 19: 4008.

Donald, C.M. 1968. The breeding of crop ideotypes. Euphytica, 17: 385-403.

Gale, M.D., Atkinson, M.D., Chinoy, C.N., Harcourt, R.L., Jia, J., Li, Q.Y., and Devos, K.M. 1995. Genetic maps of hexaploid wheat. In Proceedings of the 8th International Wheat Genetic Symposium, Beijing, China, 20-25 July 1993. Edited by Z.S. Li and Z.Y. Xin. Agricultural Scientech Press, Beijing, China. pp. 29-40.

Gupta, P.K., Balyan, H.S., Edwards, K.J., Isaac, P., Korzun, V., Röder, M., Gautier, M.-F., Joudrier, P., Schlatter, A.R., Dubcovsky, J., De la Pena, R.C., Khairallah, M., Penner, G., Hayden, M.J., Sharp, P., Keller, B., Wang, R.C.C., Hardouin, J.P., Jack, P., and Leroy, P. 2002. Genetic mapping of 66 new microsatellite (SSR) loci in bread wheat. Theor. Appl. Genet. 105: 413-422.

Guyomarc'h, H., Sourdille, P., Charmet, G., Edwards, K.J., and Bernard, M. 2002. Characterization of polymorphic microsatellite markers from Aegilops tauschii and transferability to the D-genome of bread wheat. Theor. Appl. Genet. 104: 1164-1172.

Hoisington, D., Khairallah, M., and González-de-León, D. 1994. Laboratory protocols: CIMMYT Applied Molecular Genetics Laboratory. 2nd ed. CIMMYT, Mexico, D.F., Mexico.
Huang, L., Brooks, S.A., Li, W.L., Fellers, J.P., Trick, H.N., and Gill, B.S. 2003. Map-based cloning of leaf rust resistance gene Lr21 from the large and polyploid genome of bread wheat. Genetics, 164: 655-664.

Inagaki, M.N., Pfeiffer, W.H., Mergoum, M., and Mujeeb-Kazi, A. 1998. Variation of the crossability of durum wheat with maize. Euphytica, 104: 17-23.

Jiang, C., and Zeng, Z.B. 1995. Multiple-trait analysis of genetic mapping for quantitative trait loci. Genetics, 140: 1111-1127.

Kammholz, S.J., Campbell, A.W., Sutherland, M.W., Hollamby, G.J., Martin, P.J., Eastwood, R.F., Barclay, I., Wilson, R.E., Brennan, P.S., and Shepard, J.A. 2001. Establishment and characterization of wheat genetic mapping populations. Aust. J. Agric. Res. 52: 1079-1088.

Lander, E.S., Green, P., Abrahamson, J., Barlow, A., Daly, M.J., Lincoln, S.E., and Newburg, L. 1987. MAPMAKER: an interactive computer package for constructing primary genetic linkage maps of experimental and natural populations. Genomics, 1: 174-181.

Li, W.L., Nelson, J.C., Chu, C.Y., Shi, L.H., Huang, S.H., and Liu, D.J. 2002. Chromosomal locations and genetic relationships of tiller and spike characters in wheat. Euphytica, 125: 357-366.

Ling, H.Q., Zhu, Y., and Keller, B. 2003. High-resolution mapping of the leaf rust disease resistance gene $\mathrm{Lrl}$ in wheat and characterization of BAC clones from the Lrl locus. Theor. Appl. Genet. 106: 875-882.

Liu, Y., and Tsunewaki, K. 1991. Restriction fragment length polymorphism (RFLP) analysis in wheat. II. Linkage maps of the RFLP sites in common wheat. Jpn. J. Genet. 66: 617-633.

Ma, Z.Q., Röder, M., and Sorrells, M.E. 1996. Frequencies and sequence characteristics of di-, tri-, and tetra-nucleotide microsatellites in wheat. Genome, 39: 123-130.

Marino, C.L., Nelson, J.C., Lu, Y.H., Sorrells, M.E., Leroy, P., Tuleen, N.A., Lopes, C.R., and Hart, G.E. 1996. Molecular genetic maps of the group 6 chromosomes of hexaploid wheat (Triticum aestivum L. em. Thell.). Genome, 39: 359-366.

McIntosh, R.A., Hart, G.E., Devos, K.M., Gale, M.D., and Rogers, W.J. 1998. Catalogue of gene symbols for wheat. Vol. 5. In. Proceedings of the 9th International Wheat Genetics Symposium, Saskatoon, Sask., Canada, 2-7 August 1998. University Extension Press, University of Saskatchewan, Saskatoon, Sask. pp. 77-83.

Messmer, M.M., Keller, M., Zanetti, S., and Keller, B. 1999. Genetic linkage map of a wheat $\times$ spelt cross. Theor. Appl. Genet. 98: $1163-1170$.

Nachit, M.M., Elouafi, I., Pagnotta, M.A., El Saleh, A., Iacono, E., Labhilili, M., Asbati, A., Azrak, M., Hazzam, H., Benscher, D., Khairallah, M., Ribaut, J.-M., Tanzarella, O.A., Porceddu, E., and Sorrells, M.E. 2001. Molecular linkage map for an intraspecific recombinant inbred population of durum wheat (Triticum turgidum L. var. durum). Theor. Appl. Genet. 102: 177-186.

Nelson, J.C., Sorrells, M.E., Van Deynze, A.E., Lu, Y.H., Atkinson, M., Bernard, M., Leroy, P., Faris, J.D., and Anderson, J.A. 1995a. Molecular mapping of wheat: major genes and rearrangements in homoeologous groups 4, 5, and 7. Genetics, 141: 721-731.

Nelson, J.C., Van Deynze, A.E., Autrique, E., Sorrells, M.E., Lu, Y.H., Merlino, M., Atkinson, M., and Leroy, P. 1995b. Molecular mapping of wheat. Homoeologous group 2. Genome, 38: 516-524.

Nelson, J.C., Van Deynze, A.E., Autrique, E., Sorrells, M.E., Lu, Y.H., Negre, S., Bernard, M., and Leroy, P. 1995c. Molecular 
mapping of wheat. Homoeologous group 3. Genome, 38: 525533.

Niwata, E., Suenaga, K., and Kuroda, S. 1994. Segregation of RAPD markers among wheat doubled haploid lines derived from wheat $\times$ maize crosses. Jpn. J. Breed. 44(Suppl. 2): 197.

Paillard, S., Schnurbusch, T., Winzeler, M., Messmer, M., Sourdille, P., Abderhalden, O., Keller, B., and Schachermayr, G. 2003. An integrative genetic linkage map of winter wheat (Triticum aestivum L.). Theor. Appl. Genet. 107: 1235-1242.

Peng, J.H., Fahima, T., Röder, M.S., Huang, Q.Y., Dahan, A., Li, Y.C., Grama, A., and Nevo, E. 2000. High-density molecular map of chromosome region harboring stripe-rust resistance genes $\mathrm{Yr} 52 \mathrm{H}$ and $\mathrm{Yr} 15$ derived from wild emmer wheat, Triticum dicocoides. Genetica, 109: 199-210.

Pestsova, E., Ganal, M.W., and Röder, M.S. 2000. Isolation and mapping of microsatellite markers specific for the D genome of bread wheat. Genome, 43: 689-697.

Rajaram, S., and van Ginkel, M. 1996. Yield potential debate: Germplasm vs. methodology, or both. In Increasing yield potential in wheat: breaking the barriers. Edited by M.P. Reynolds, S. Rajaram, and A. McNab. CIMMYT, Mexico, D.F., Mexico. pp. 11-18.

Reddy, M.P., Sarla, N., and Siddiq, E.A. 2002. Inter simple sequence repeat (ISSR) polymorphism and its application in plant breeding. Euphytica, 128: 9-17.

Richards, R.A. 1988. A tiller inhibitor gene in wheat and its effect on plant growth. Aust. J. Agric. Res. 39: 749-757.

Röder, M.S., Korzun, V., Wendehake, K., Plaschke, J., Tixier, M.H., Leroy, P., and Ganal, M.W. 1998. A microsatellite map of wheat. Genetics, 149: 2007-2023.

Sanguinetti, C.J., Neto, E.D., and Simpson, A.J.G. 1994. Rapid silver staining and recovery of PCR products separated on polyacrylamide gels. BioTechniques, 17: 915-919.

Singh, R.P. $1992 a$. Association between gene Lr34 for leaf rust resistance and leaf tip necrosis in wheat. Crop Sci. 32: 874-878.

Singh, R.P. 1992b. Genetic association of leaf rust resistance gene Lr34 with adult plant resistance to stripe rust in bread wheat. Phytopathology, 82: 835-838.

Song, Q.J., Fickus, E.W., and Cregan, P.B. 2002. Characterization of trinucleotide SSR motifs in wheat. Theor. Appl. Genet. 104: 286-293.
Sourdille, P., Snape, J.W., Cadalen, T., Charmet, G., Nakata, N., Bernard, S., and Bernard, M. 2000. Detection of QTLs for heading time and photoperiod response in wheat using a doubledhaploid population. Genome, 43: 487-494.

Stephenson, P., Bryan, G., Kirby, J., Collins, A., Devos, K., Busso, C., and Gale, M. 1998. Fifty new microsatellite loci for the wheat genetic map. Theor. Appl. Genet. 97: 946-949.

Suenaga, K., and Nakajima, K. 1993. Segregation of genetic markers among wheat doubled haploid lines derived from wheat $x$ maize crosses. Euphytica, 65: 145-152.

Suenaga, K., Tamaki, M., and Nakajima, K. 1991. Influence of wheat (Triticum aestivum) and maize (Zea mays) genotypes on haploid wheat production in crosses between wheat and maize. Bull. Natl. Inst. Agrobiol. Resour. 6: 131-142.

Suenaga, K., William, M., van Beem, J., and Hoisington, D.A. 2002. Towards the development of molecular markers for phasic development genes in wheat. In First International Symposium on Crop Genomics and Genetic Improvement, Wuhan, China, 21-15 September 2002.

Van Deynze, A.E., Dubcovsky, J., Gill, K.S., Nelson, J.C., Sorrells, M.E., Dvorák, J., Gill, B.S., Lagudah, E.S., McCouch, S.R., and Appels, R. 1995. Molecular-genetic maps for group1 chromosomes of Triticeae species and their relation to chromosomes in rice and oat. Genome, 38: 45-59.

Williams, K.J., Taylor, S.P., Bogacki, P., Pallotta, M., Bariana, H.S., and Wallwork, H. 2002. Mapping of the root lesion nematode (Pratylenchus neglectus) resistance gene Rlnn1 in wheat. Theor. Appl. Genet. 104: 874-879.

Worland, A.J., Korzun, V., Röder, M.S., Ganal, M.W., and Law, C.N. 1998. Genetic analysis of the dwarfing gene $R h t 8$ in wheat. Part II. The distribution and adaptive significance of allelic variants at the Rht8 locus of wheat as revealed by microsatellite screening. Theor. Appl. Genet. 96: 1110-1120.

Worland, A.J., Sayers, E.J., and Korzun, V. 2001. Allelic variation at the dwarfing gene $R h t 8$ locus and its significance in international breeding programmes. Euphytica, 119: 155-159.

Wu, K.-S., Jones, R., Danneberger, L., and Scolnik, P.A. 1994. Detection of microsatellite polymorphisms without cloning. Nucleic Acids Res. 22: 3257-3258.

Zeng, Z.B. 1994. Precision mapping of quantitative trait loci. Genetics, 136: 1457-1468. 